\title{
Greater central adiposity resulting from increased market integration is associated with elevated C-reactive protein levels in older women from the Republic of Vanuatu
}

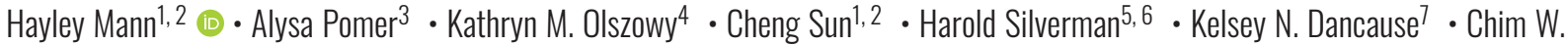

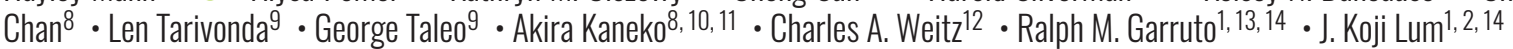 \\ 1 Department of Anthropology, Binghamton University, Binghamton, NY \\ ${ }^{2}$ Laboratory of Evolutionary Anthropology and Health, Binghamton University, \\ Binghamton, NY \\ ${ }^{3}$ Department of Chronic Disease Epidemiology, Yale School of Public Health, New \\ Haven, CT \\ ${ }^{4}$ Department of Anthropology, New Mexico State University, Las Cruces NM \\ ${ }^{5}$ Laboratory of Biomedical Science, The Feinstein Institute for Medical Research, \\ Manhasset, NY \\ ${ }^{6}$ Hofstra North Shore-LIJ School of Medicine at Hofstra University, Hempstead, \\ NY \\ ${ }^{8}$ Department of Parasitology, Graduate School of Medicine, Osaka City Univer- \\ sity, Osaka, Japan \\ ${ }^{9}$ Ministry of Health, Port Vila, Vanuatu \\ ${ }^{10}$ Island Malaria Group, Department of Microbiology, Tumor and Cell Biology \\ (MTC), Karolinska Institutet, Stockholm, Sweden \\ ${ }^{11}$ Institute of Tropical Medicine, Nagasaki University, Nagasaki, Japan \\ 12 Department of Anthropology, Temple University, Philadelphia, PA \\ ${ }^{13}$ Laboratory of Biomedical Anthropology and Neurosciences, Binghamton Uni- \\ versity, Binghamton, NY \\ ${ }^{14}$ Department of Biological Sciences, Binghamton University, Binghamton, NY
}

7 Départment des sciences de l'activité physique, Université du Quebec à Montréal, Montréal QC, Canada

\section{Citation:}

Mann, H. et al. (2021), Greater central adiposity resulting from increased market integration is associated with elevated C-reactive protein levels in older women from the Republic of Vanuatu, Human Biology and Public Health 2.

https://doi.org/10.52905/hbph.v2.20.

Received: 2021-06-23

Accepted: 2021-08-17

Published: 2021-12-22

\section{Copyright: \\ This is an open access article distributed under the terms of the Creative Commons Attribution License which permits unrestricted use, distribution, and reproduction in any medium, provided the original author and source are credited.}

\section{Conflict of Interest:}

There are no conflicts of interest.

\section{Correspondence to: \\ Hayley Mann \\ email: hmann3@binghamton.edu.}

\section{Keywords:}

Body Mass Index, central adiposity, Pacific Islands, Melanesians, market integration

\begin{abstract}
Objective We characterized the relationship between circulating C-reactive protein (CRP) levels and nine anthropometric measures of body composition to identify the best anthropometric predictors of CRP in Ni-Vanuatu women.

Sample and Methods Anthropometric data and blood spot samples were collected from sixty-four Ni-Vanuatu female participants (age 35-78 years) on five islands with varying degrees of market integration, cultural change, and obesity. CRP concentration was determined with a high-sensitivity ELISA (hSCRP) assay and then compared to nine different anthropometric measurements.
\end{abstract}

Results BMI was significantly correlated with CRP ( $p=0.047$, $\left.\mathrm{r}^{2}=0.249\right)$. Among the eight additional anthropometrics, BIA $\left(\mathrm{p}=0.040, \mathrm{r}^{2}=0.257\right)$, waist-circumference $\left(\mathrm{p}=0.009, \mathrm{r}^{2}=0.325\right)$ and suprailiac skinfold $\left(\mathrm{p}=0.003, \mathrm{r}^{2}=0.373\right)$ were better predictors of CRP than BMI. Moreover, our stepwise selection model indicated that the suprailiac skinfold explained $14 \%$ of CRP level variance.

Conclusions The BMI-CRP correlation coefficient for Ni-Vanuatu women falls within the range of previously reported values for East Asian populations with whom they share genetic ancestry. Furthermore, the best anthropometric predictors of CRP levels were waist circumference and suprailiac skinfold thickness. These measures capture central adiposity and are more closely associated with elevated CRP level and cardiovascular disease risk than fat distributed elsewhere on the body. Ni-Vanuatu in urban settings

Take home message for students High obesity rates in the Pacific Islands are correlated with processed foods which are available via increasing market integration. CRP level is most correlated with central adiposity, and waist circumference is most conveniently measured in the field. Since nearly everyone owns gardens, consumption of processed foods is a personal choice in Vanuatu. 
with high market integration are at greater risk for obesity, which is associated with elevated CRP levels. However, because nearly all $\mathrm{Ni}$-Vanuatu still retain horticultural knowledge and land ownership, consumption of processed, imported foods is largely determined by degree of market integration and personal choice. Therefore, health interventions focusing on sustainable traditional food practices are feasible.

\section{Introduction}

Since the 1980s, global obesity prevalence has doubled and is now considered a universal human health problem (WHO Expert Consultation 2004). Moreover, 55\% of this global rise in mean body mass index (BMI) occurred in rural areas. For lowand middle-income countries, data also suggests that rural mean BMI is rising at similar rates to urban settings, especially for women (NCD Risk Factor Collaboration 2019). The marketing of inexpensive, processed food has resulted in the overconsumption of nutrient poor dietary items, while lifestyle changes associated with modernization has led to a decrease in physical activity (Popkin et al. 2012; Swinburn et al. 2011). Currently, the Pacific Islands have some of the world's highest rates of obesity (Gill 2006). Many Pacific Island nations are lower income with poor infrastructure. Some islands also have a double burden of non-communicable diseases (NCDs) and infectious diseases, which makes public health interventions more challenging. Furthermore, Pacific Islanders are significantly underrepresented in health literature and are a medically underserved population with unequal access to the healthcare (Ghosh 2003).

Long periods of colonization, de-population from introduced diseases, resource exploitation and more recently, global market integration have resulted in a series of sociocultural changes that continue to negatively impact indigenous health throughout the Pacific. In Melanesia, European contact began in the 1500s and first contacts by explorers, missionaries, whalers, sandalwooders, and miners continued through the 20th century. Indigenous people suffered various devastations including the loss of traditional lands and culture, and the introduction of new diseases (Allen 1968; MacClancy 1981). In the second half of the nineteenth century, exploitation of Melanesians for plantation/cash crop labor intensified while epidemics and population loss continued (MacClancy 1981). Allied and Japanese forces occupied much of Melanesia during World War II, significantly increasing infrastructure and the availability of imported processed foods in some regions. By the end of WWII, postcontact dietary items such as cooking oil, refined sugar, tinned meats, beef, dairy products, and bread had become food staples on some of the islands (Dancause et al. 2011; 2013). Beginning with Papua New Guinea in 1975, many pacific island nations gained their independence. On larger islands, urban administrative and commercial centers emerged characterized by greater infectious disease control, tourism, and more convenient food choices, but poor nutrition and exercise resulting in higher obesity (Dancause et al. 2011). Obesity therefore became a public health concern in Melanesia after WWII and has continued to increase over time.

Currently, the ten countries with the highest rates of adult obesity are all located in Micronesia and Polynesia, with Nauru (61\%) and the Cook Islands (55.9\%) being the top two (Central Intelligence Agency 2021). Between 1980-2008, mean BMI in the Cook Islands and Nauru increased at four times the global rate (McLennan and Ulijaszek 2015). The countries comprising Melanesia have less obesity; especially in endemic malarious regions. For example, 
Vanuatu, the Solomon Islands and Papua New Guinea have obesity rates of $25.2 \%$, $22.5 \%$ and $21.3 \%$, respectively (Central Intelligence Agency 2021). Although the lowand middle-income countries of the Western Pacific Region have lower obesity rates, non-communicable diseases (NCDs) such as cardiovascular diseases (CVDs), diabetes and cancer still account for $50 \%$ of premature deaths in individuals under 70 years of age (Shin and Varghese 2014). With improved infectious disease control measures on some of the islands (Kaneko et al. 2000), increases in tourism (Dancause et al. 2011) and worsening climate change (Swinburn et al. 2011), the obesity rate in Melanesia will likely approach those of Micronesia and Polynesia.

To help address NCD-related public health concerns, research in the Western Pacific region has focused on analyzing anthropometric measures within a context of changing behaviors and physical activities (Dancause et al. 2011; Olszowy et al. 2015). Individual obesity has been estimated in a variety of ways for different studies. BMI and waist circumference thresholds are commonly used to assess individual CVD risk (DeLoach et al. 2014; Ding et al. 2015; Schafer et al. 2011). However, these measurements cannot distinguish fat mass from fat-free mass, so the corresponding estimated CVD risk category may not be accurate for some individuals, particularly athletes (Dancause et al. 2010; Klein et al. 2007; Neovius et al. 2006). In comparison to North American and European populations, Asian populations have a greater predisposition for developing abdominal obesity and a higher risk for developing CVDs at lower BMIs (Forouhi et al. 2001; WHO Expert Consultation 2004). This observation led to the development of different BMI cutoff points in various Asian populations; specifically, the BMI obesity cutoff value for health intervention was lowered (Popkin 2004; WHO Expert
Consultation 2004). Likely reflecting their shared genetic ancestry with East Asians, Pacific Islanders also possess greater abdominal obesity (Dancause et al. 2011). It has therefore been suggested that the World Health Organization (WHO) action guidelines for Asian populations should also be applied to Pacific Islanders in Western Melanesia (Dancause et al. 2010). For a more precise measure of body composition, bioelectrical impedance analysis (BIA) has also been used to determine body fat percentage. Limitations of BIA equipment include reliance on technology, variable body electrode placement, and also different body fat percentage prediction models that are dependent upon sex, body type, population-specific equations, and other assumptions (Dancause et al. 2010; Neovius et al. 2006; Sergi et al. 2017). Skinfold thickness anthropometrics provide a more direct measure of fat tissue, but there is less population data associated with skinfold measures and the usage of calipers may be uncomfortable for some participants. Ultimately, measuring individual BMI and waist circumference may be more feasible in remote clinical and field site settings.

Chronic low-grade inflammation associated with obesity is also known to play a major role in the development of cardiovascular diseases (Brooks et al. 2010; Khoo et al. 2011; Pearson et al. 2003). C-reactive protein (CRP) is an inflammatory response biomarker and assessing CRP levels improves the accuracy of predicting cardiovascular disease-related outcomes in patients (Brooks et al. 2010; Danesh et al. 2000; Pearson et al. 2003). CRP testing is widely utilized by human biologists and medical researchers in their studies to better characterize the relationships among obesity, elevated CRP level and CVD outcomes across different populations (Choi et al. 2012; Khoo et al. 2011; McDade et al. 2009; Sung et al. 2014). The American Heart 
Association (AHA) has provided recommendations for using high sensitivity CRP (hsCRP) testing to help identify CVD risk when included with measures of adiposity. Currently, the AHA's three CRP categories for CVD risk are low $(<1.0 \mathrm{mg} / \mathrm{L})$, intermediate $(1.0-2.9 \mathrm{mg} / \mathrm{L})$, and high $(>3.0 \mathrm{mg} / \mathrm{L})$. Elevated CRP level (i.e., above $1.0 \mathrm{mg} / \mathrm{L}$ ) is an indication of low-grade inflammation associated with obesity and risk for developing CVDs (Pearson et al. 2003). However, the cross-population clinical utility of currently recommended AHA CRP category cutoff values for CVD risk has been questioned (Sung et al. 2014). When controlling for BMI and other CVD-related risk factors (e.g., smoking), average CRP levels for East and Southeast Asian populations are lower than American, European, and South Asian populations (Choi et al. 2012; Khoo et al. 2011; McDade et al. 2009; Sung et al. 2014). McDade et al. (2009) reported that American women are 3.9 times more likely to have a high-risk CRP concentration of $>3.0 \mathrm{mg} / \mathrm{L}$ than Filipino women with the same BMI. A lower CRP level average in East Asians, however, does not necessarily mean the risk for developing a CVD is reduced. For instance, Sung et al. (2014) showed that a Korean population with predominantly low CRP levels $(<1.0$ $\mathrm{mg} / \mathrm{L}$ ) had an elevated risk for CVD-related events with only minor increases in CRP level. It has also been observed that populations differ in regard to how strongly BMI correlates with CRP level. In particular, East Asian populations tend to have a weaker association between BMI and CRP levels than North American or European populations (Choi et al. 2012; Doumatey et al. 2010; Jeemon et al. 2011; Lim et al. 2006; Saito et al. 2003). These studies show that ancestry can modify the relationship between CRP and CVD risk, which raises the possibility that the standardized CRPassociated CVD risk categories may be underestimating the number of individuals who have an elevated risk for CVD in certain populations (Sung et al. 2014).

This study includes Ni-Vanuatu women residing on five different islands of The Republic of Vanuatu. Amongst islands of Vanuatu, there is a gradient of infectious disease control and market access to imported and processed food items. Along with low genetic diversity among Ni-Vanuatu, the characteristic variation of rural and more urbanized islands can be studied as a natural experimental model (Dancause etal. 2011). Although processed foods are currently available throughout Vanuatu, nearly all Ni-Vanuatu still retain traditional land (due to historical, diseaseinduced depopulation) and gardens resulting in minimal food insecurity, which is an uncommon feature for a lower-income county. Research in Vanuatu has provided valuable insight into human health transitions (Dancause et al. 2011; Olszowy et al. 2015). As yet, efforts to assess the relationship between body composition and CRP level in Melanesian populations have been limited. The current study is our first attempt to add protein biomarker analyses to our ongoing longitudinal examination of the epidemiological transition underway in Vanuatu that we have monitored since 2007 (Dancause et al. 2010). We examined the relationship between nine anthropometric measures and CRP levels in blood spots collected from older Ni-Vanuatu women age 35-72 from different islands with different degrees of market integration. Previous analyses focused on surveys of diet and behavior, as well as anthropometric measurements of body composition, blood pressure, and other chronic disease correlates. These demonstrated that older women displayed the greatest variation in health metrics. For this initial analysis, older and mainly postmenopausal Ni-Vanuatu women participants were chosen with a wide range of BMIs because they were expected to result in a broader range of CRP 
levels than less variable younger women (Sites et al. 2002; Visser et al. 1999) or men (Choi et al. 2012). Because BMI is widely used in clinical research and CVD risk assessment across different populations (Peters et al. 2018), CRP levels for Ni-Vanuatu women were first analyzed within the recommended standard WHO BMI categories (World Health Organization 2000a). Next, we evaluated which anthropometric measurements of body composition were the best predictors of CRP levels. In comparison to measures of peripheral and upper body adiposity or whole-body anthropometric measures, we hypothesized that more direct measurements of central adiposity would better predict CRP levels in Ni-Vanuatu women and thus, be better measures of CVD risk than BMI.

\section{Samples and Methods}

\section{Study population}

Current patterns of genetic, linguistic, geographic affinities, and analyses of ancient DNA indicate that Ni-Vanuatu are admixed descendants of two distinct populations; initial Holocene ( 3 kya) settlers from Island Southeast Asia and extensive post-settlement gene flow from neighboring Pleistocene settlers of Near Oceania (Kayser 2010; Lipson et al. 2018; Lum and Cann 1998; Skoglund et al. 2016). Currently, some Ni-Vanuatu populations possess genetic markers associated with both Melanesia and Polynesia (Vilar 2010), reflecting a 1000-year history of settlement and ongoing gene flow between the regions. Vanuatu is also currently experiencing economic development and cultural change at varying rates across the archipelago (Olszowy et al. 2015). Of the five islands surveyed, the most economically developed island is Efate which includes the urban and malaria-free capital, Port Vila. Nguna is located just off the north shore of Efate with easy access to Port Vila infrastructure and market resources. Aneityum is geographically rural but has been experiencing increased tourism and development due to the elimination of malaria in 1991 (Kaneko et al. 2000). The islands Futuna and Ambae are also rural, and villages are comprised of extended families practicing subsistence horticulture. At the time of sample collection in 2011, both Ambae and Nguna were burdened by malaria. Although European contact with Vanuatu first occurred during the early 1600s, major dietary transitions did not occur until the introduction of French and British food items by colonialists in the late 1800s (e.g., cooking oil, refined sugar, beef, dairy products, and bread) (Dancause et al. 2011; 2013). Currently, some processed foods can be purchased throughout Vanuatu; however, most Ni-Vanuatu still possess traditional horticultural knowledge and own land that is suitable for sustainable, continuous food production.

\section{Anthropometric measures of body fat}

In June and July of 2011, nine different anthropometric measures were collected from Ni-Vanuatu women participants $(n=242)$, who resided on one of five islands of Vanuatu (Ambae, Futuna, Aneityum, Nguna, and Efate). Everyone who wanted to participate in the study were invited to do so. Skinfold measurements were taken to the nearest $1 \mathrm{~mm}$ in triplicate using Lange skinfold calipers (Cambridge, MA) and circumferences were taken in triplicate using non-elastic anthropometric tapes to the nearest $0.1 \mathrm{~cm}$; the mean of all measurements at each site were used in analyses. All measurements were 
Table 1 Description of anthropometricsa and Pearson correlation coefficients with CRP

\begin{tabular}{cccccc|c|c|c|c|c|}
\hline & $\begin{array}{c}\text { Mid-lower } \\
\text { arm skinfold }\end{array}$ & $\begin{array}{c}\text { Subscapular } \\
\text { skinfold }\end{array}$ & $\begin{array}{c}\text { Triceps } \\
\text { skinfold }\end{array}$ & $\begin{array}{c}\text { Lower arm } \\
\text { circ. }\end{array}$ & $\begin{array}{c}\text { Upper arm } \\
\text { circ. }\end{array}$ & BMI & BIA & $\begin{array}{c}\text { Waist } \\
\text { circ. }\end{array}$ & $\begin{array}{c}\text { Suprail- } \\
\text { iac } \\
\text { skinfold }\end{array}$ \\
\hline $\begin{array}{c}\text { Body } \\
\text { location }\end{array}$ & peripheral & upper body & peripheral & peripheral & peripheral & $\begin{array}{c}\text { total } \\
\text { body }\end{array}$ & $\begin{array}{c}\text { lower } \\
\text { body }\end{array}$ & central & central \\
\hline$r^{2}$ & 0.131 & 0.174 & 0.190 & 0.209 & 0.223 & 0.249 & 0.257 & 0.325 & 0.373 \\
\hline p-value & 0.302 & 0.176 & 0.133 & 0.098 & 0.077 & $0.047^{*}$ & $0.040^{*}$ & $0.009^{* *}$ & $0.003^{* *}$ \\
\hline$n$ & 64 & 62 & 64 & 64 & 64 & 64 & 64 & 63 & 62 \\
\hline
\end{tabular}

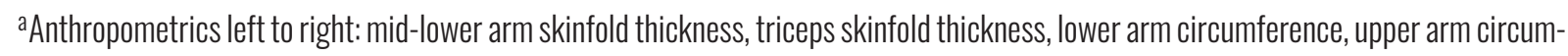
ference, subscapular skinfold thickness, body-mass index (BMI), BIA (bio-electrical impedance), waist circumference, suprailiac skinfold thickness. ${ }^{b}$ Body fat location measured for each anthropometric. CRP statistics include Pearson correlation coefficient, probability > $|r|$ under $\mathrm{HO}$ : Rho=0, and number of individuals included for each measurement.

completed according to standard accepted guidelines (Lohman et al. 1988). Peripheral fat measurements included: upper and lower arm circumferences, mid-lower arm skinfold (maximum circumference of the lower arm), and triceps skinfold. Subscapular skinfold thickness was measured as an estimate of upper body fat. Central adiposity was estimated from suprailiac skinfold thickness and waist circumference (approximately $2 \mathrm{~cm}$ above the navel). Participant weight and height were measured for BMI (weight $[\mathrm{kg}] /$ height squared $\left[\mathrm{m}^{2}\right]$ ). Percent body fat was also determined via BIA, where electrode placement was at the feet resulting in an electrical current passing through the abdomen (Tanita Body Composition Analyzer digital scale \#TBF-521 (Arlington Heights, IL). BIA was therefore predominantly a measure of lower body fat.

\section{Blood spot filter collection and study subset selection}

In addition to anthropometrics, filter paper blood spot samples were collected from the same Ni-Vanuatu women participants. Blood spots were dried, placed in zip lock bags for transport, and then were exposed to ambient tropical temperatures for up to a month before being stored at $-80^{\circ} \mathrm{C}$. For this study, sixty-four blood spot samples from female participants age 35-76 (Suppl. Table S1) were selected based on BMI variation $\left(16.2-47.7 \mathrm{~kg} / \mathrm{m}^{2}\right)$. To evaluate if the sample subset $(n=64)$ was representative of the larger dataset from $2011(n=242)$, three characteristics of each dataset were compared to test the null hypothesis of no difference. First, the means of the BMIs were compared using a two-sample t-test which resulted in $\mathrm{t}=0.367, \mathrm{p}=0.715$. Second, the variances of the BMIs were compared using a chi-square test which resulted in $\chi^{2}=$ $74.95, p=0.250$. Individual BMIs were then classified into one of four internationally utilized categories (WHO, 2000a): underweight, average, overweight, and obese (Suppl. Table S2). These classification distributions were compared by a chi-square test which resulted in $\chi^{2}=2.1, p=0.549$. None of the three hypotheses can be rejected, indicating the subset analyzed for CRP is a minimally biased representation of the larger population dataset.

\section{CRP analysis}

A 3.2mm disc from each blood spot filter paper $(n=64)$ was taken and eluted overnight 
at $4^{\circ} \mathrm{C}$ in $250 \mu \mathrm{l}$ of PBS Tween-20 $(1 \mathrm{ml} / \mathrm{L})$ solution followed by $300 \mathrm{rpm}$ shaking at room temperature for 60 minutes the next day (McDade et al., 2004). The eluate was diluted to 1:1000 and then added to an Invitrogen hsCRP (high-sensitivity CRP) human ELISA kit (\#KHA0032). An incremental CRP concentration standard range of $0-2.1 \mathrm{mg} / \mathrm{L}$ was used and the ELISA plate was analyzed on a microplate reader at a wavelength of $490 \mathrm{~nm}$.

\section{Statistical analysis}

BMI and ELISA hsCRP levels from the same individual were compared in a box plot graph (Figure 1). Six individuals exceeded the $2.1 \mathrm{mg} / \mathrm{L}$ maximum CRP value for the assay standard curve. These samples were included in the statistical analyses using the value of $2.1 \mathrm{mg} / \mathrm{L}$ (a likely underestimate of their actual circulating CRP levels). Supplemental questionnaire data collected did not indicate any major health problems that might affect CRP levels (i.e., recent injury, illness, or infection). To determine the anthropometric measurement most correlated with CRP level, a Pearson correlation was performed between CRP and nine anthropometric measurements of body fat (Table 1). A few individuals were missing some measurements, so each comparison included 62-64 participants' data. For a more detailed view of the relationship between suprailiac skinfold thickness and CRP level, we generated a fit plot with 95\% confidence intervals (Figure 2). We then applied a stepwise (bidirectional) regression analysis with a set entrance and stay level at 0.05 (Suppl. Tables S3-S5).

\section{Results}

Women from each BMI category and ELISA hsCRP level from the same indi- vidual were compared using a box plot graph (Figure 1). The average CRP level for all $64 \mathrm{Ni}-$ Vanuatu women was $0.97 \mathrm{mg} / \mathrm{L}$. For the underweight BMI category $(n=4)$, the CRP average was $0.41 \mathrm{mg} / \mathrm{L}$ and only one sample exceeded $1.0 \mathrm{mg} / \mathrm{L}$. The CRP average for the average $(n=27)$ and overweight $(n=17)$ BMI categories were 0.89 $\mathrm{mg} / \mathrm{L}$ and $0.91 \mathrm{mg} / \mathrm{L}$, respectively. However, the range of CRP levels for these two BMI categories were broad $(0.52 \mathrm{mg} / \mathrm{L}$ to $2.1 \mathrm{mg} / \mathrm{L})$. The obese BMI category $(\mathrm{n}=16)$ had the highest CRP average $(1.2 \mathrm{mg} / \mathrm{L})$ with the majority of samples $(n=12 / 16)$ being greater than the subclinical inflammation threshold of $1.0 \mathrm{mg} / \mathrm{L}$. However, six women in the obese category likely exceeded the assay detection limit of 2.1 $\mathrm{mg} / \mathrm{L}$. Therefore, the actual means for CRP average in the overweight and obese BMI categories is likely higher. The number of $\mathrm{Ni}$-Vanuatu women from different islands for each BMI category is also included. Individuals from Nguna and Efate, the islands with the greatest market integration, comprise over half the overweight and obese categories $(n=18 / 33)$.

Table 1 shows the Pearson correlations between the nine anthropometrics and CRP. The anthropometric measurements that were significantly correlated with CRP levels include BIA $\left(p=0.257, r^{2}=0.040\right)$, BMI ( $\left.p=0.249, r^{2}=0.047\right)$, waist circumference $\left(p=0.325, r^{2}=0.009\right)$, and suprailiac skinfold thickness $\left(p=0.373, r^{2}=0.003\right)$. Peripheral and upper body measures of fat were not significantly correlated with CRP levels. The anthropometric measurements correlated most with CRP level were the suprailiac skinfold $(p=0.003)$ and waist circumference $(p=0.009)$. Based on the ANOVA analysis that resulted in that p-value of less than 0.05 , we proceeded with a stepwise regression (Suppl. Tables S3-S5). We observed that by incorporating $\mathrm{CRP}$ as the input value, no variable was removed, and the fitted model was 


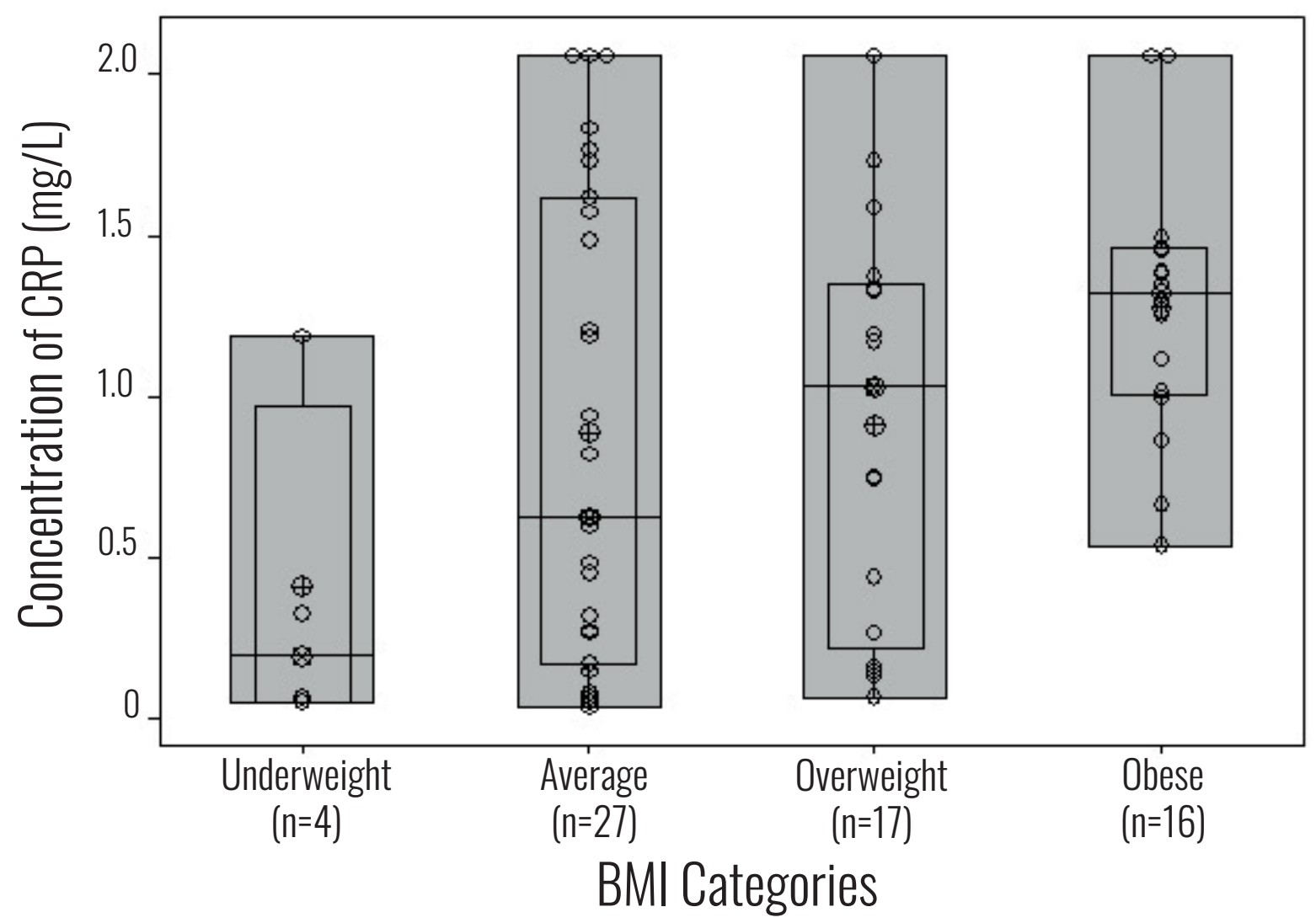

Figure 1 WHO BMl categories compared to CRP concentration (mg/L) from the same individual.

reproducing the similar correlation as in the ANOVA analysis. The suprailiac skinfold was the only anthropometric to enter the model and remain, explaining approximately $14 \%\left(r^{2}=0.139\right)$ of CRP variance. Figure 2 illustrates the regression trend line with $95 \%$ confidence intervals relating suprailiac skinfold to CRP level.

\section{Discussion}

Sociocultural changes resulting from colonization, resource exploitation and more recently, global market integration have caused the world's highest rates of obesity throughout the Pacific Islands. In Vanuatu, the obesity rate is highest in the urban capital of Efate, but obesity has also increased in peri-urban (e.g., Nguna) and rural islands (e.g., Aneityum) due to growing tourism, greater access to non-traditional dietary items and infectious disease control (Dancause et al. 2011). The increasing risk for developing a NCD are therefore an alarming public health concern for Ni-Vanuatu. The need for more accurate CVD risk assessments led to a re-consideration of BMI cut-off action points for Asians and Pacific Islanders (WHO Expert Consultation 2004). High-sensitivity CRP testing can improve the accuracy of CVD risk assessments (Brooks et al. 2010; Danesh et al. 2000; Pearson et al. 2003); however, studies show that there are population differences in baseline CRP level 2012)(e.g., Choi et al.. When developing public health strategies for non-European populations, human biologists and other health researchers should therefore be aware of how population diversity may affect interpreting 


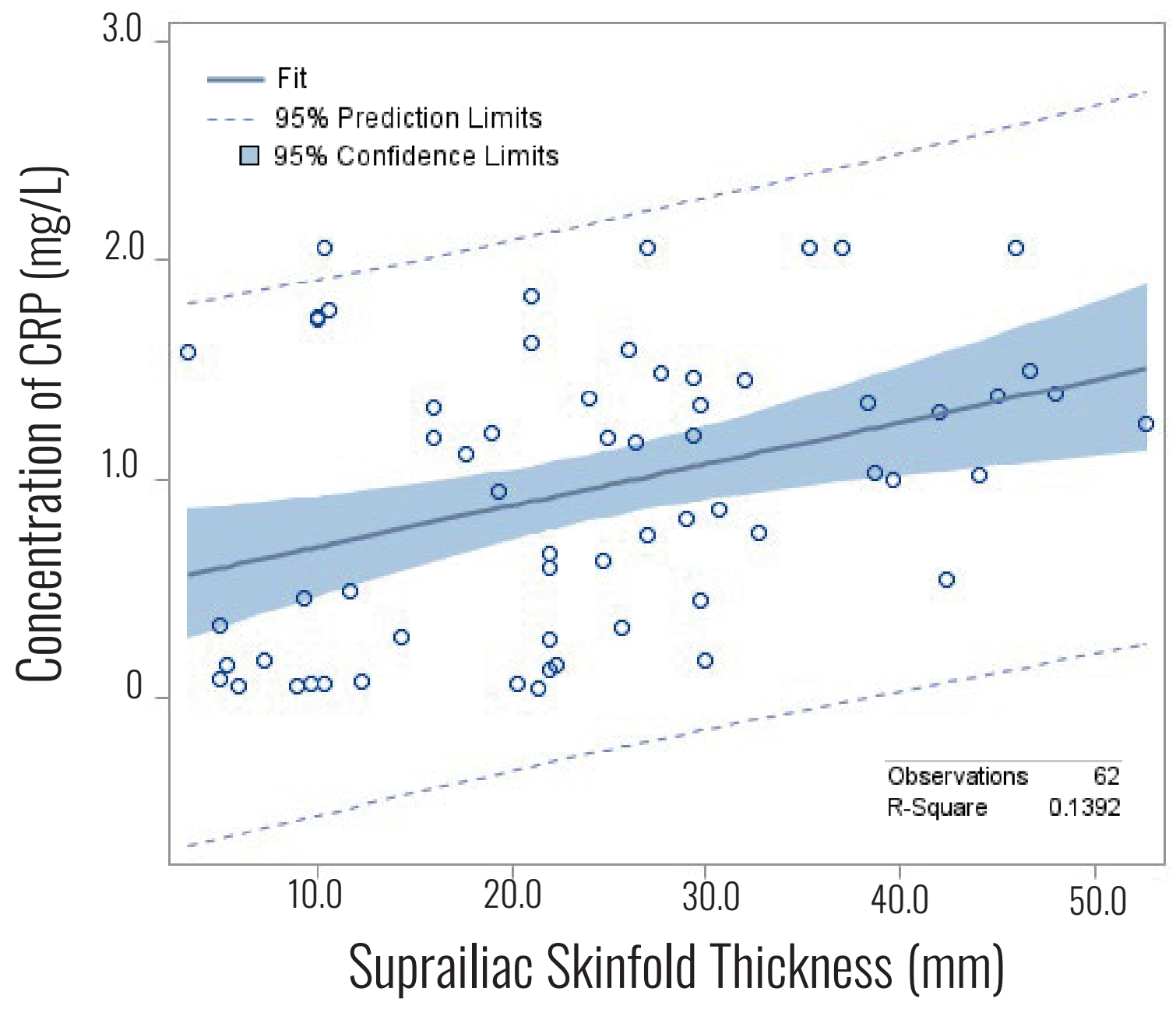

Figure 2 Fit plot for CRP level versus suprailiac skinfold thickness from the same individual.

hsCRP data and corresponding NCD-risk data.

This study includes older Ni-Vanuatu women because they have a greater range of BMIs and are disproportionately at risk for developing a NCD (Olszowy et al. 2015; Sites et al. 2002; Visser et al. 1999). We first analyzed Ni-Vanuatu CRP levels across the four the WHO BMI categories (Figure 1) recommended for international usage (World Health Organization 2000a). Our results indicate that the range of CRP levels for the average and overweight $(n=44)$ BMI categories are broad $(0.52 \mathrm{mg} / \mathrm{L}$ to 2.1 $\mathrm{mg} / \mathrm{L})$. Moreover, the majority $(\mathrm{n}=12 / 16)$ of Ni-Vanuatu women in the obese BMI category have low-grade inflammation
(>1.0 mg/L). Pacific Islanders have a predisposition for storing excess abdominal fat, so they are at a higher risk for developing CVDs at lower BMIs (Dancause et al. 2010; Forouhi et al. 2001; McKeigue et al. 1991; WHO Expert Consultation 2004). The revised WHO guidelines for Asian populations (World Health Organization 2000b) suggest that if the BMI clinical action cutoff value for identifying overweight Asian individuals is $23 \mathrm{~kg} / \mathrm{m} 2$ (Pan and Yeh 2008; WHO Expert Consultation 2004), then obesity should be a public health concern if a significant portion of the population has a BMI of $>23 \mathrm{~kg} / \mathrm{m} 2$. Some Asian countries (e.g., Thailand and Vietnam) have now adapted this guideline to help identify 
more individuals at risk for noncommunicable diseases (Jitnarin et al. 2011; Trinh et al. 2009) and Dancause et al. (2010) also advocated for its usage in Vanuatu. For the current study, if WHO clinical action values are applied to Ni-Vanuatu women, then nine women who currently fall within the average BMI category would be re-categorized as overweight. CRP values for five of these women also indicate they have subclinical inflammation, which puts them at greater risk for CVDs. Currently, the AHA has defined standard health risk categories for hsCRP; however, there is uncertainty if AHA hsCRP cutoff values for CVD risk can be accurately utilized for a diversity of populations (Sung et al. 2014).

Anthropometric measurements that explicitly estimate abdominal fat tissue have been shown to be better predictors of individual CRP levels and CVD risk than BMI (Ford et al. 2004; McDade et al. 2009; Peters et al. 2018). This is likely because fat stored near the abdomen is more metabolically active and is known to increase CRP levels (Brooks et al. 2010; Park et al. 2005). Our CRP correlation analysis showed that peripheral and upper body measures (lower and upper arm, triceps, and subscapular) were not significantly correlated with CRP levels. BMI and BIA were significantly correlated; however, suprailiac skinfold thickness and waist circumference measurements were better predictors of CRP levels (Table S3). BMI is an indicator of body size and BIA (for this study) measures lower body fat to lean mass, whereas suprailiac skinfold thickness and waist circumference are central abdomen measures. Our results suggest that abdominal fat was the strongest mediator of CRP levels in Ni-Vanuatu women, which supports our hypothesis. Further supporting this finding is the observation that East Asians tend to have a lower correlation between BMI and CRP levels in comparison to other populations (Choi et al. 2012; Sung et al. 2014). Previously reported BMI-CRP correlation values ranged from $0.13-0.39$ for East Asian women and 0.32-0.6 for European and African American women (Choi et al. 2012). The BMI-CRP correlation value for Ni-Vanuatu women was 0.25 , within the reported range for East Asian women, but less than expected for European or African women. Furthermore, a recent study that included 500,000 participants from the UK found that measures of central adiposity were more strongly associated with myocardial infarction than BMI, especially among women (Peters et al. 2018). A centrally located pattern of body fat distribution is also likely more pathogenic in Ni-Vanuatu women, so direct measures of central adiposity may be the most informative anthropometrics when estimating CVD risk.

Compared to BMI and BIA, there are additional benefits to using suprailiac skinfold thickness and waist circumference measurements in remote sampling locations, including ease of calculation and minimal equipment requirements (i.e., calipers and a tape measure). In this study, suprailiac skinfold thickness was the most significantly correlated anthropometric with CRP, but waist circumference had a comparable value (Table 1). Suprailiac skinfold thickness may be considered as an intrusive measure because it requires privacy, gender matched survey staff and participants, and substantial training for reproducible data collection. Thus, waist circumference may ultimately be the easiest, most meaningful anthropometric measurement for researchers in the field to collect. The World Health Organization (2000a) has recommended waist circumference values to help identify central obesity, which includes $94 \mathrm{~cm}$ for men and $80 \mathrm{~cm}$ for women. For Asian populations, $90 \mathrm{~cm}$ for men and $80 \mathrm{~cm}$ for women have been suggested (An et al. 2013; World Health Organization 2000b). However, a waist circumference 
value that is clinically significant for identifying an increased risk for CVDs needs to be determined specifically for Ni-Vanuatu and other Pacific Islander populations.

Lowering CRP levels can help reduce the risk for developing CVDs (Brooks et al. 2010).

Thus, identifying different physiological and environmental factors that increase CRP levels can in turn be useful for clinical and public health interventions. So far, BMI has been cited as being a large single contributor to individual CRP levels. For instance, previous studies for European and Taiwanese populations found that BMI accounted for $15 \%$ and $11.9 \%$ of the total variance in CRP levels, respectively (Huang et al. 2013; Kathiresan et al. 2006). Suprailiac skinfold thickness remained in our stepwise model and explained approximately 14\% of CRP level variance (Tables S3-S5). Suprailiac skinfold thickness is therefore the greatest single contributor to CRP variance in our dataset. However, in addition to excess central adiposity, environmental factors may also help explain Ni-Vanuatu CRP level variance. For example, environmental factors associated with elevated CRP levels include greater consumption of high-glycemic index foods and psychosocial stress (McDade et al. 2006; Neuhouser et al. 2012; Steptoe et al. 2007). These are features typical of a more westernized diet and greater degree of market integration. Olszowy et al. (2015) included a larger sample of women from this study in Vanuatu. Their results show that Nguna and Efate, the islands experiencing the greatest degree of market integration, also had the highest rates of obesity among women ( $28.3 \%$ and $43.4 \%$, respectively). In our sample set, individuals from Nguna and Efate comprised over half the overweight and obese BMI categories (Figure 1). These islands are characterized by energy rich, high sodium and low nutrient, processed foods, as well as decreased phys- ical activity, and increased socioeconomic status (Dancause et al. 2010; Olszowy et al. 2015). Because market integration and cultural change leads to increased adiposity in Ni-Vanuatu women (Olszowy et al. 2015), there is also a greater risk for elevated CRP levels. A larger sample from different islands will be necessary to identify specific risk factors with the greatest impact.

Uncharacterized hereditary factors could also be contributing to differences in baseline CRP levels. One estimate suggests that serum CRP interindividual variability is $35-40 \%$ heritable (Pankow et al. 2001). Several studies have also found correlations between CRP polymorphisms and serum level in different populations (e.g., Ghaffari et al. 2014; Zacho et al. 2010). For example, genetic contribution to CRP level variance for North American and Chinese populations was found to be $1.4 \%$ and $2.4 \%$, respectively (Kathiresan et al. 2006; Huang et al. 2013). As stated previously, Pacific Island populations are underrepresented in widely used genomic datasets (e.g., 1000 Genomes and gnomAD) and medical genetics research, so it is still unknown if $\mathrm{Ni}$-Vanuatu will genetically resemble other Pacific Island populations and/or if there is population-specific CRP gene variation that is clinically relevant.

Finally, an optimistic note for improving health status in Vanuatu is that although it is a lower-income country, there is minimal food insecurity. This is because all Ni-Vanuatu have access to substantial arable land, possess traditional horticultural knowledge and food can be grown all year. In addition to growing their own food, Ni-Vanuatu can also purchase processed food on most islands. This is significant because a greater reliance on traditional practices can help maintain a healthier lifestyle, whereas greater market integration increases the risk for obesity (Dancause et al. 2011). Notably, Vanuatu differs from most other lowincome nations which are often lacking in 
a diversity of dietary options and access to fresh food. Overconsumption of processed food can therefore be viewed as a choice in Vanuatu and this awareness could be emphasized in local public health programs. because Vanuatu has low food insecurity and processed foods are consumed largely by choice rather than need, public health education and other inexpensive, nonbiomedical interventions may be fruitful in Vanuatu.

\section{Conclusions}

Our results show that the suprailiac skinfold thickness and waist circumference, both measures of central obesity, were the best anthropometric predictors of CRP levels in older Ni-Vanuatu woman. These results are consistent with previous studies on Asian populations as well as medical findings demonstrating that abdominal obesity is linked to CRP levels and risk for CVDs. Although suprailiac skinfold thickness and waist circumference are both easy to measure, waist circumference may ultimately be the most convenient to use in a field setting. Analyzing blood spot samples for biomarkers has also been widely used by field researchers to complement healthrelated studies. By utilizing this approach, our results show that hsCRP testing can also determine which Ni-Vanuatu individuals are likely at greater risk for CVDrelated outcomes within the overweight and obese WHO categories. In order to more accurately determine elevated CVD risk in Ni-Vanuatu, additional clinical and behavioral studies will be necessary to determine clinically significant cutoff points for measures of central adiposity and CRP levels. To examine the contribution of inherited variation compared to environmental factors on circulating CRP levels, future studies can also assess CRP gene variation from populations experiencing differential market integration. Finally, the gradient of obesity prevalence is largely a reflection of the degree of market integration and differential availability of processed foods among the islands. However,

\section{Ethics}

This project was approved by the Binghamton University Institutional Review Board (protocol number \#1578-10). We also obtained permissions from the Vanuatu Ministry of Health and prior to sampling in each village, we received permission from local chiefs and the community at large through public meetings. Informed consent was obtained from each study participant.

\section{Acknowledgements}

We would like to acknowledge the Vanuatu Ministry of Health, the leadership of each community we surveyed, and the many health workers and local assistants who aided us in data collection for this project. We also thank the participants, without whose willingness to participate, this project could not have been possible. This study was funded by the following: Wenner-Gren Foundation for Anthropological Research; Binghamton University Laboratory of Evolutionary Anthropology and Health; Harpur College Grants in Support of Research, Scholarship and Creative Work. 


\section{References}

Allen, M. R. (1968). The establishment of Christianity and cash-cropping in a New Hebridean community. The Journal of Pacific History 3 (1), 25-46. https://doi.org/10.1080/00223346808572123.

An, Y./Yi, S./Fitzpatrick, A./Gupta, V./Prak, P. R./Oum, S./LoGerfo, J. P. (2013). Appropriate body mass index and waist circumference cutoff for overweight and central obesity among adults in Cambodia. PloS One 8 (10), e77897. https://doi.org/10.1371/journal.pone.0077897.

Brooks, G. C./Blaha, M. J./Blumenthal, R. S./Brooks, Gabriel C./Blaha, Michael J./Blumenthal, Roger S. (2010). Relation of C-reactive protein to abdominal adiposity. The American Journal of Cardiology 106 (1), 56-61. https://doi.org/10.1016/j.amjcard.2010.02.017.

Central Intelligence Agency (2021). Obesity - adult prevalence rate. The World Factbook, Langley (VA).

Choi, J./Joseph, L./Pilote, L. (2012). Obesity and C-reactive protein in various populations: a systematic review and meta-analysis. Obesity Reviews 14 (3), 232-244. https://doi.org/10.1111/obr.12003.

Dancause, K. N./DeHuff, C./Soloway, L. E./Vilar, M./Chan, C./Wilson, M./Tarivonda, L./Regenvanu, R./Kaneko, A./Garruto, R. M./Lum, J. K. (2011). Behavioral changes associated with economic development in the South Pacific: health transition in Vanuatu. American Journal of Human Biology 23 (3), 366-376. https://doi.org/10.1002/ajhb.21146.

Dancause, K. N./Vilar, M./DeHuff, C./Wilson, M./Soloway, L. E./Chan, C./Lum, J. K./Garruto, R. M. (2010). Relationships between body size and percent body fat among Melanesians in Vanuatu. Asia Pacific Journal of Clinical Nutrition 19 (3), 425-431.

Dancause, K. N./Vilar, M./Wilson, M./Soloway, L. E./DeHuff, C./Chan, C./Tarivonda, L./Regenvanu, R./Kaneko, A./Lum, J. K./Garruto, R. M. (2013). Behavioral risk factors for obesity during health transition in Vanuatu, South Pacific. Obesity 21 (1), E98-E104. https://doi.org/10.1002/oby.20082.

Danesh, J./Whincup, P./Walker, M./Lennon, L./Thomson, A./Appleby, P./Gallimore, J. R./Pepys, M. B. (2000). Low grade inflammation and coronary heart disease: prospective study and updated meta-analyses. BMJ 321 (7255), 199-204. https://doi.org/10.1136/bmj.321.7255.199.

DeLoach, S./Falkner, B./Keith, S. W./Gidding, S. S. (2014). Obesity associated inflammation in African American adolescents and adults. The American Journal of the Medical Sciences 347 (5), 357-363. https://doi.org/10.1097/MAJ.0b013e31829555fo.
Ding, D./Wang, M./Su, D./Hong, C./Li, X./Yang, Y./Zhang, Y./Hu, G./Ling, W. (2015). Body mass index, high-sensitivity C-reactive protein and mortality in Chinese with coronary artery disease. PloS One 10 (8), e0135713. https://doi.org/10.1371/journal.pone.0135713.

Doumatey, A. P./Lashley, K. S./Huang, H./Zhou, J./Chen, G./Amoah, A./Agyenim-Boateng, K./Oli, J./Fasanmade, O./Adebamowo, C. A./Adeyemo, A. A./Rotimi, C. N. (2010). Relationships among obesity, inflammation, and insulin resistance in African Americans and West Africans. Obesity 18 (3), 598-603. https://doi.org/10.1038/oby.2009.322.

Ford, E. S./Giles, W. H./Mokdad, A. H./Myers, G. L. (2004). Distribution and correlates of C-reactive protein concentrations among adult US women. Clinical Chemistry 50 (3), 574-581. https://doi.org/10.1373/clinchem.2003.027359.

Forouhi, N. G./Sattar, N./McKeigue, P. M. (2001). Relation of C-reactive protein to body fat distribution and features of the metabolic syndrome in Europeans and South Asians. International Journal of Obesity 25 (9), 1327-1331. https://doi.org/10.1038/sj.ijo.0801723.

Ghaffari, M. A./Sede, S. A./Rashtchizadeh, N./Mohammadzadeh, G./Majidi, S. (2014). Association of CRP gene polymorphism with CRP levels and Coronary Artery Disease in Type 2 Diabetes in Ahvaz, southwest of Iran. Bioimpacts 4 (3), 133. https://doi.org/10.15171/bi.2014.006.

Ghosh, C. (2003). Healthy people 2010 and Asian Americans/Pacific islanders: defining a baseline of information. American Journal of Public Health 93 (12), 2093-2098. https://doi.org/10.2105/ajph.93.12.2093.

Gill, T. (2006). Epidemiology and health impact of obesity: an Asia Pacific perspective. Asia Pacific Journal of Clinical Nutrition 15, Suppl:3-14.

Huang, C.-C./Chung, C.-M./Leu, H.-B./Lin, T.-H./Hung, S.-l./Wu, T.-C./Huang, P.-H./Lin, S.-J./Pan, W.-H./Chen, J.-W. (2013). Genetic variation in C-reactive protein in ethnic Chinese population in Taiwan. European Journal of Clinical Investigation 43 (5), 449-456. https://doi.org/10.1111/eci.12067.

Jeemon, P./Prabhakaran, D./Ramakrishnan, L./Gupta, R./Ahmed, F./Thankappan, K. R./Kartha, C.

C./Chaturvedi, V./Reddy, K. S. (2011). Association of high sensitive C-reactive protein (hsCRP) with established cardiovascular risk factors in the Indian population. Nutrition \& Metabolism 8 (1), 1-8. https://doi.org/ 10.1186/1743-7075-8-19.

Jitnarin, N./Kosulwat, V./Rojroongwasinkul, N./Boonpraderm, A./Haddock, C. K./Poston, W. S.C./Jitnarin, N./Poston, W. S. C. (2011). Prevalence of overweight and obesity in Thai population: results of the National Thai Food Consumption Survey. Eating and Weight Disorders 16 (4), e242-e249. https://doi.org/10.1007/BF03327467. 
Kaneko, A./Taleo, G./Kalkoa, M./Yamar, S./Kobayakawa, T./Björkman, A. (2000). Malaria eradication on islands. Lancet 356 (9241), 1560-1564. https://doi.org/10.1016/ S0140-6736(00)03127-5.

Kathiresan, S./Larson, M. G./Vasan, R. S./Guo, C.Y./Gona, P./Keaney Jr, J. F./Wilson, P. W. F./NewtonCheh, C./Musone, S. L./Camargo, A. L./Keaney, J. F./Drake, J. A./Levy, D./O’Donnell, C. J./Hirschhorn, J. N./Benjamin, E. J. (2006). Contribution of clinical correlates and $13 \mathrm{C}$-reactive protein gene polymorphisms to interindividual variability in serum C-reactive protein level. Circulation 113 (11), 1415-1423. https://doi.org/10.1161/CIRCULATIONAHA.105.591271.

Kayser, M. (2010). The human genetic history of Oceania: near and remote views of dispersal. Current Biology 20 (4), R194-R201.

https://doi.org/10.1016/j.cub.2009.12.004.

Khoo, C. M./Sairazi, S./Taslim, S./Gardner, D./Wu, Y./Lee, J./van Dam, R. M./Tai, E. S. (2011). Ethnicity modifies the relationships of insulin resistance, inflammation, and adiponectin with obesity in a multiethnic Asian population. Diabetes Care 34 (5), 1120-1126. https://doi.org/10.2337/dc10-2097.

Klein, S./Allison, D. B./Heymsfield, S. B./Kelley, D. E./Leibel, R. L./Nonas, C./Kahn, R. (2007). Waist circumference and cardiometabolic risk: a consensus statement from shaping America's health: Association for Weight Management and Obesity Prevention; NAASO, the Obesity Society; the American Society for Nutrition; and the American Diabetes Association. The American Journal of Clinical Nutrition 85 (5), 1197-1202. https://doi.org/10.1093/ajcn/85.5.1197.

Lim, S./Jang, H. C./Lee, H. K./Kimm, K. C./Park, C./Cho, N. H. (2006). The relationship between body fat and C-reactive protein in middle-aged Korean population. Atherosclerosis 184 (1), 171-177. https://doi.org/10.1016/j.atherosclerosis.2005.04.003.

Lipson, M./Skoglund, P./Spriggs, M./Valentin, F./Bedford, S./Shing, R./Buckley, H./Phillip, I./Ward, G. K./Mallick, S./Rohland, N./Broomandkhoshbacht, N./Cheronet, O./Ferry, M./Harper, T. K./Michel, M./Oppenheimer, J./Sirak, K./Stewardson, K./Auckland, K./Hill, A. V. S./Maitland, K./Oppenheimer, S. J./Parks, T./Robson, K./Williams, T. N./Kennett, D. J./Mentzer, A. J./Pinhasi, R./Reich, D. (2018). Population turnover in remote Oceania shortly after initial settlement. Current Biology 28 (7), 1157-1165. https://doi.org/10.1016/j.cub.2018.02.051.

Lohman, T. G./Roche, A. F./Martorell, R. (Eds.) (1988). Anthropometric standardization reference manual. Champaign, Ill., Human Kinetics Books.

Lum, J. K./Cann, R. L. (1998). mtDNA and language support a common origin of Micronesians and Polynesians in Island Southeast Asia. American Journal of Physical Anthropology 105 (2), 109-119. https://doi. org/10.1002/(SICI)1096-8644(199802)105:2<109::AIDAJPA1>3.3.CO;2-M.
MacClancy, J. (1981). To kill a bird with two stones. A short history of Vanuatu. Port Vila, Vanuatu Cultural Centre.

McDade, T. W./Hawkley, L. C./Cacioppo, J. T. (2006). Psychosocial and behavioral predictors of inflammation in middle-aged and older adults: the Chicago health, aging, and social relations study. Psychosomatic Medicine 68 (3), 376-381. https://doi.org/10.1097/01.psy.0000221371.43607.64.

McDade, T. W./Rutherford, J. N./Adair, L./Kuzawa, C. (2009). Population differences in associations between C-reactive protein concentration and adiposity: comparison of young adults in the Philippines and the United States. The American Journal of Clinical Nutrition 89 (4), 1237-1245. https://doi.org/10.3945/ajcn.2008.27080.

McKeigue, P. M./Shah, B./Marmot, M. G. (1991). Relation of central obesity and insulin resistance with high diabetes prevalence and cardiovascular risk in South Asians. Lancet 337 (8738), 382-386. https://doi.org/10. 1016/0140-6736(91)91164-P.

McLennan, A. K./Ulijaszek, S. J. (2015). Obesity emergence in the Pacific islands: why understanding colonial history and social change is important. Public Health Nutrition 18 (8), 1499-1505. https://doi.org/10.1017/S136898001400175X.

NCD Risk Factor Collaboration (2019). Rising rural body-mass index is the main driver of the global obesity epidemic in adults. Nature 569 (7755), 260. https://doi. org/10.1038/s41586-019-1171-x.

Neuhouser, M. L./Schwarz, Y./Wang, C./Breymeyer, K./Coronado, G./Wang, C. Y./Noar, K./Song, X./Lampe, J. W. (2012). A low-glycemic load diet reduces serum C-reactive protein and modestly increases adiponectin in overweight and obese adults. Journal of Nutrition 142 (2), 369-374. https://doi.org/10.3945/jn.111.149807.

Neovius, M./Hemmingsson, E./Freyschuss, B./Uddén, J. (2006). Bioelectrical impedance underestimates total and truncal fatness in abdominally obese women. Obesity 14 (10), 1731-1738. https://doi.org/10.1038/oby.2006.199.

Olszowy, K. M./Pomer, A./Dancause, K. N./Sun, C./Silverman, H./Lee, G./Chan, C. W./Tarivonda, L./Regenvanu, R./Kaneko, A./Weitz, C. A./Lum, J. K./Garruto, R. M. (2015). Impact of modernization on adult body composition on five islands of varying economic development in Vanuatu. American Journal of Human Biology 27 (6), 832-844. https://doi.org/10.1002/ajhb.22734.

Pan, W.-H./Yeh, W.-T. (2008). How to define obesity? Evidence-based multiple action points for public awareness, screening, and treatment: an extension of Asian-Pacific recommendations. Asia Pacific Journal of Clinical Nutrition 17 (3), 370. 
Pankow, J. S./Folsom, A. R./Cushman, M./Borecki, I. B./Hopkins, P. N./Eckfeldt, J. H./Tracy, R. P. (2001). Familial and genetic determinants of systemic markers of inflammation: the NHLBI family heart study. Atherosclerosis 154 (3), 681-689. https://doi.org/10. 1016/S0021-9150(00)00586-4.

Park, H. S./Park, J. Y./Yu, R. (2005). Relationship of obesity and visceral adiposity with serum concentrations of CRP, TNF- $\alpha$ and IL-6. Diabetes Research and Clinical Practice 69 (1), 29-35. https://doi.org/10.1016/j.diabres.2004.11.007.

Pearson, T. A./Mensah, G. A./Alexander, R. W./Anderson, J. L./Cannon III, R. O./Criqui, M./Fadl, Y. Y./Fortmann, S. P./Hong, Y./Myers, G. L./Cannon, R. O./Rifai, N./Smith, S. C./Taubert, K./Tracy, R. P./Vinicor, F. (2003). Markers of inflammation and cardiovascular disease: application to clinical and public health practice: a statement for healthcare professionals from the Centers for Disease Control and Prevention and the American Heart Association. Circulation 107 (3), 499-511. https://doi.org/10.1161/01.CIR.0000052939.59093.45.

Peters, S. A. E./Bots, S. H./Woodward, M. (2018). Sex differences in the association between measures of general and central adiposity and the risk of myocardial infarction: results from the UK Biobank. Journal of the American Heart Association 7 (5), e008507. https://doi.org/10.1161/JAHA.117.008507.

Popkin, B. M. (2004). The nutrition transition: an overview of world patterns of change. Nutrition Reviews 62 (7, Suppl. Pt 2), S140-S143. https://doi.org/10.1111/j. 1753-4887.2004.tb00084.x.

Popkin, B. M./Adair, L. S./Ng, S. W. (2012). Global nutrition transition and the pandemic of obesity in developing countries. Nutrition Reviews 70 (1), 3-21. https://doi. org/10.1111/j.1753-4887.2011.00456.x.

Saito, M./Ishimitsu, T./Minami, J./Ono, H./Ohrui, M./Matsuoka, H. (2003). Relations of plasma high-sensitivity C-reactive protein to traditional cardiovascular risk factors. Atherosclerosis 167 (1), 73-79. https://doi.org/10. 1016/S0021-9150(02)00380-5.

Schafer, M. H./Ferraro, K. F./Williams, S. R. (2011). Low socioeconomic status and body mass index as risk factors for inflammation in older adults: conjoint influence on C-reactive protein? Journals of Gerontology Series A: Biomedical Sciences and Medical Sciences 66 (6), 667-673. https://doi.org/10.1093/gerona/glr009.

Sergi, G./Rui, M. de/Stubbs, B./Veronese, N./Manzato, E. (2017). Measurement of lean body mass using bioelectrical impedance analysis: a consideration of the pros and cons. Aging Clinical and Experimental Research 29 (4), 591-597. https://doi.org/10.1007/s40520-016-0622-6.

Shin, H.-R./Varghese, C. (2014). WHO Western Pacific regional action plan for the prevention and control of NCDs (2014-2020). Epidemiology and Health 36, e2014007. https://doi.org/10.4178/epih/e2014007.
Sites, C. K./Toth, M. J./Cushman, M./L’Hommedieu, G. D./Tchernof, A./Tracy, R. P./Poehlman, E. T. (2002). Menopause-related differences in inflammation markers and their relationship to body fat distribution and insulin-stimulated glucose disposal. Fertility and Sterility 77 (1), 128-135. https://doi.org/10.1016/S00150282(01)02934-X.

Skoglund, P./Posth, C./Sirak, K./Spriggs, M./Valentin, F./Bedford, S./Clark, G. R./Reepmeyer, C./Petchey, F./Fernandes, D./Fu, Q./Harney, E./Lipson, M./Mallick, S./Novak, M./Rohland, N./Stewardson, K./Abdullah, S./Cox, M. P./Friedlaender, F. R./Friedlaender, J. S./Kivisild, T./Koki, G./Kusuma, P./Merriwether, D. A./Ricaut, F./Wee, J. T. S./Patterson, N./Krause, J./Pinhasi, R./Reich, D. (2016). Genomic insights into the peopling of the Southwest Pacific. Nature 538 (7626), 510-513. https://doi.org/10.1038/nature19844.

Steptoe, A./Hamer, M./Chida, Y. (2007). The effects of acute psychological stress on circulating inflammatory factors in humans: a review and meta-analysis. Brain, Behavior, and Immunity 21 (7), 901-912. https://doi.org/10.1016/j.bbi.2007.03.011.

Sung, K.-C./Ryu, S./Chang, Y./Byrne, C. D./Kim, S. H. (2014). C-reactive protein and risk of cardiovascular and all-cause mortality in 268803 East Asians. European Heart Journal 35 (27), 1809-1816. https://doi.org/10.1093/eurheartj/ehu059.

Swinburn, B. A./Sacks, G./Hall, K. D./McPherson, K./Finegood, D. T./Moodie, M. L./Gortmaker, S. L. (2011). The global obesity pandemic: shaped by global drivers and local environments. Lancet 378 (9793), 804-814. https://doi.org/10.1016/S0140-6736(11)608131.

Trinh, O. T. H./Nguyen, N. D./Phongsavan, P./Dibley, M. J./Bauman, A. E. (2009). Prevalence and risk factors with overweight and obesity among Vietnamese adults: Caucasian and Asian cut-offs. Asia Pacific Journal of Clinical Nutrition 18 (2), 226-233. Available online at https://search.informit.org/doi/10.3316/informit.683855345951353 (accessed 11/19/2021).

Vilar, M. G. (2010). Origins and post-settlement gene flow among culturally and linguistically distinct Pacific populations. Doctoral dissertation. [New York], Binghamton University.

Visser, M./Bouter, L. M./McQuillan, G. M./Wener, M. H./Harris, T. B. (1999). Elevated C-reactive protein levels in overweight and obese adults. JAMA 282 (22), 2131-2135. https://doi.org/10.1001/jama.282.22.2131.

WHO Expert Consultation (2004). Appropriate bodymass index for Asian populations and its implications for policy and intervention strategies. Lancet 363 (9403), 157-163. https://doi.org/10.1016/S0140-6736(03)152683. 
World Health Organization (2000a). Obesity: preventing and managing the global epidemic. Report of a WHO consultation. World Health Organization technical report series 894, 1-253. PMID: 11234459.

World Health Organization. Regional Office for the Western Pacific (2000b). The Asia-Pacific perspective: redefining obesity and its treatment. Sydney : Health Communications Australia. https://apps.who.int/iris/handle/10665/206936 (accessed 12/22/2021).
Zacho, J./Tybjærg-Hansen, A./Nordestgaard, B. G./Tybjaerg-Hansen, A. (2010). C-reactive protein and all-cause mortality: the Copenhagen City Heart Study. European Heart Journal 31 (13), 1624-1632. https://doi.org/10.1093/eurheartj/ehq103. 


\section{Appendix}

\section{Supplementary Tables}

Table S1 Distribution of participant age for each island

\begin{tabular}{|l|c|c|c|} 
& $n$ & Mean & Std. \\
\hline All Islands & 64 & 51.6 & 11.1 \\
\hline Ambae & 13 & 46.7 & 6.2 \\
\hline Futuna & 13 & 51.8 & 9.2 \\
\hline Aneityum & 13 & 52.6 & 14.6 \\
\hline Nguna & 13 & 47.5 & 8.3 \\
\hline Efate & 12 & 64.6 & 11.4
\end{tabular}

Table $\mathbf{2}$ WHO BMI categories with number of study participants from each island

\begin{tabular}{l|c|c|c|c|} 
& $\begin{array}{c}\text { Underweight } \\
\left(<18.5 \mathrm{~kg} / \mathrm{m}^{2}\right)\end{array}$ & $\begin{array}{c}\text { Average } \\
\left(18.5-24.5 \mathrm{~kg} / \mathrm{m}^{2}\right)\end{array}$ & $\begin{array}{c}\text { Overweight } \\
\left(25.0-29.9 \mathrm{~kg} / \mathrm{m}^{2}\right)\end{array}$ & $\begin{array}{c}\text { Obese } \\
\left(\geq 30.0 \mathrm{~kg} / \mathrm{m}^{2}\right)\end{array}$ \\
\hline Island & 2 & & & \\
\hline Ambae & 0 & 8 & 3 & 1 \\
\hline Futuna & 0 & 7 & 4 & 4 \\
\hline Aneityum & 1 & 2 & 2 & 4 \\
\hline Nguna & 1 & 3 & 6 & 6 \\
\hline Efate & 4 & 27 & 17 & 16
\end{tabular}

Table S3 ANOVA for interactivity between CRP and other anthropometrics

\begin{tabular}{|c|c|c|c|c|c|c|}
\hline Source & DF & Sum of Squares & Mean Square & F Value & $\operatorname{Pr}>\mathrm{F}$ & $r^{2}$ \\
\hline Model $^{*}$ & 1 & 3508467 & 3508467 & 9.70 & 0.003 & 0.139 \\
\hline Error & 60 & 21696263 & 361604 & & & \\
\hline Corrected Total & 61 & 25204730 & & & & \\
\hline
\end{tabular}

Table S4 Stepwise bidirectional regression analysis with anthropometric input

\begin{tabular}{|l|c|c|c|c|c|c|}
\hline Step & Variable Entered & Variable Removed & Partial R-square & Model R-square & F value & $\operatorname{Pr}>$ F \\
\hline 1 & Suprailiac Sknflds & (none) & 0.1392 & 0.1392 & 9.7 & 0.0028 \\
\hline
\end{tabular}

Table S5 CRP regression model equation ${ }^{\mathrm{a}}$

\begin{tabular}{|l|c|c|c|}
\hline Variable & Parameter Estimate & F Value & Pr > F \\
\hline Intercept & 4.9468792 & 8.85 & 0.0042 \\
\hline Supra_Sknflds & 0.01910462 & 9.70 & 0.0014 \\
\hline
\end{tabular}

${ }^{\mathrm{a} C R P}(\mathrm{mg} / \mathrm{L})=4.947+0.019 *[$ Suprailiac skinfold $(\mathrm{mm})]$ 